\title{
Predictive Factors for Hepatocellular Carcinoma Occurrence or Recurrence after Direct-Acting Antiviral Agents in Patients with Chronic Hepatitis C
}

\author{
Yu Yoshimasu, Yoshihiro Furuichi, Yoshitaka Kasai, Hirohito Takeuchi, Katsutoshi Sugimoto, Ikuo Nakamura, \\ Takao Itoi
}

Department of

Gastroenterology and

Hepatology, Tokyo Medical

University, Tokyo,

Japan

\author{
Address for correspondence: \\ Yoshihiro Furuichi \\ Department of \\ Gastroenterology and \\ Hepatology \\ Tokyo Medical University \\ 6-7-1 Nishishinjuku, \\ Shinjuku-ku, Tokyo 160-0023, \\ Japan \\ furuichi@tokyo-med.ac.jp
}

Received: 14.12.2018

Accepted: 20.02.2019

\begin{abstract}
Background \& Aims: Direct-acting antiviral agents (DAAs) and the risk of hepatocellular carcinoma (HCC) is controversially reported in the literature. The primary endpoints of this study were to clarify the cumulative incidence and recurrence rate of HCC after DAA treatment. The secondary endpoints were to identify the factors associated with the occurrence or recurrence of HCC after DAAs treatment.

Methods: Of $234 \mathrm{HCV}$ patients, 211 with no history of HCC (no-HCC-history group) and 23 with previous treated HCC history (HCC-history group) were treated with DAAs and followed for more than 24 weeks to determine the incidence of HCC. Platelet count, albumin, a-fetoprotein (AFP) level, L3\%, the FIB-4 index and APRI scores were analyzed as possible factors associated with HCC occurrence and recurrence. An intergroup comparison was made of the cumulative incidence of HCC. Cox proportional hazards regression was used to determine associations between blood test values and risk of HCC.

Results: The median observation period was 21 months. Cumulative incidence of HCC was higher in the HCChistory group than in the no-HCC-history group ( $\mathrm{p}<0.0001,19.0$ and 0.52 per 100 patient-years, respectively). Univariate analysis revealed platelet count, albumin, $\alpha$-fetoprotein (AFP) level, AFP-L3\%, and FIB-4 index and APRI scores at the end of DAA treatment as being significantly associated with occurrence/recurrence of HCC. Multivariate analysis revealed that AFP levels before and after the administration of DAAs and AFP-L3\% after DAA were independently associated with the occurrence/recurrence of HCC ( $p=0.045,0.043,0.005$, respectively). Conclusion: The HCC occurrence rate after DAA treatment was very low, and the recurrence rate lower than that in previous interferon reports. The AFP level and AFP-L3\% were identified as important factors in predicting occurrence/recurrence of HCC. Careful observation is needed when increased levels of AFP or AFP-L3\% after DAAs treatment are observed.
\end{abstract}

Key words: direct-acting antiviral agents - hepatocellular carcinoma - hepatitis C virus.

Abbreviations: AFP: $\alpha$-fetoprotein; APRI: AST to Platelet Ratio Index; ASV: asunaprevir; CHC: chronic hepatitis C; CT: computer tomography; DAA: direct-acting antiviral agent; DSV: daclatasvir; FIB-4, fibrosis-4; HCC: hepatocellular carcinoma; HCV: hepatitis C virus; IFN: interferon; MRI: magnetic resonance imaging; SVR: sustained virological response; US: ultrasonography.

\section{INTRODUCTION}

Infection with the hepatitis $\mathrm{C}$ virus (HCV) leads to chronic hepatitis $\mathrm{C}(\mathrm{CHC})$ and cirrhosis in approximately $20 \%$ of patients within 20 years of infection [1]. One earlier study found that hepatocellular carcinoma (HCC) occurred in approximately $3.5 \%$ of cases per year once cirrhosis was established [2]. Elimination of HCV after interferon (IFN)based therapy has been reported to reduce the risk of HCC $[3,4]$ by preventing progression to cirrhosis [5]. The recent development of direct-acting antiviral agents (DAAs) enabled a sustained virological response (SVR) in more than $90 \%$ of $\mathrm{CHC}$ patients. It remains unknown, however, whether viral eradication by means of DAAs reduces the occurrence of HCC. Recent studies suggested that DAAs increased the risk of recurrence of HCC in patients who had undergone complete resection and radiofrequency ablation $[6,7]$. This indicates the importance of establishing which factors are involved in the occurrence or recurrence of HCC after treatment with DAAs.

Our study investigated the occurrence and recurrence rates of HCC in HCV patients treated with DAAs and searched for possible predictive factors. 


\section{METHODS}

\section{Study design and patient selection}

The primary endpoints of this study were to clarify the cumulative incidence and recurrence rate of HCC after DAA treatment. The secondary endpoints were to identify the factors associated with the occurrence or recurrence of HCC.

The protocol of this retrospective cohort study was approved (Approval number: 2017-327) by the Clinical Research Ethics Committee of Tokyo Medical University and complied with the principles of the Helsinki agreement. Data obtained regarding all HCV patients treated with DAAs at this hospital between September 2014 and June 2017 was analyzed. The exclusion criteria were as follows: 1) patients with treated HCC without a complete radiologic response; 2) patients receiving IFN as part of their treatment regimen; and 3) patients who had not undergone a 6-month observation period after DAA treatment. Of the 245 patients enrolled, 11 were excluded because potential HCC nodules were detected by a second opinion on ultrasonography (US), computed tomography (CT) with contrast agent, or magnetic resonance imaging (MRI) with Gd-EOB-DTPA before DAA treatment (Fig. 1). All imaging examinations for HCC detection were performed within 2 months before starting the DAA treatment. Of a total of 234 patients, 211 had no history of HCC (noHCC-history group), while the remaining 23 had a history of previous treatment for HCC (HCC-history group). Liver stiffness was calculated by means of ultrasound elastography (Aplio 500, Toshiba Medical Systems Corp., Otawara, Japan) before DAA treatment in 68 patients. Stiffness measurement was performed 5 times and the average value determined.

\section{Hepatitis C treatment}

Direct-acting antiviral agents were selected according to the guidelines published by the Japan Society of Hepatology. The treatment regimens $(n=234)$ were as follows (Table I):
65 patients received 24 weeks of asunaprevir (ASV) and daclatasvir (DSV); 77 patients received 12 weeks of sofosbuvir (SOF) and ledipasvir (LDV); 24 patients received 12 weeks of ombitasvir (OBV) and paritaprevir (PTV) in combination with ritonavir (r); 11 patients received 12 weeks of elbasvir (EBR) and grazoprevir (GZR); and 57 patients received 12 weeks of SOF and ribavirin (RBV). An SVR was defined as a serum HCV RNA level that was undetectable at 24 weeks (ASV + DSV) or 12 weeks (others) after treatment.

\section{Clinical and radiological examination of HCC after DAA treatment}

There was no evidence of HCC on US, CT, or MRI before DAA treatment in any patient. The patients were followed up at 3-month intervals using a blood chemistry test. Abdominal examination by US, CT, or MRI was performed at intervals of 3-6 months. A definitive diagnosis of HCC was made by confirmation of the hypervascular pattern of the tumor by enhanced CT, Gd-EOB-DTPA MRI or contrast-enhanced US. The median observation period was 21 months after the completion of DAA treatment (Table I).

\section{Statistical analysis}

The cumulative incidence of HCC was retrospectively analyzed using the Kaplan-Meier method. The log-rank test was used to determine significant differences. Statistical analysis was performed using SPSS 24.0J software (SPSS Inc., Chicago, IL, USA). Values are expressed as the median and range. The Mann-Whitney U-test was used to compare patient background blood values. The factors independently associated with the occurrence or recurrence of HCC were analyzed by Cox proportional regression analysis. The chi-squared test was used to compare differences among sexes. The Wilcoxon signed rank test was used to compare liver function before and after DAA treatment. A p-value of $<0.05$ was considered to indicate a statistically significant difference.

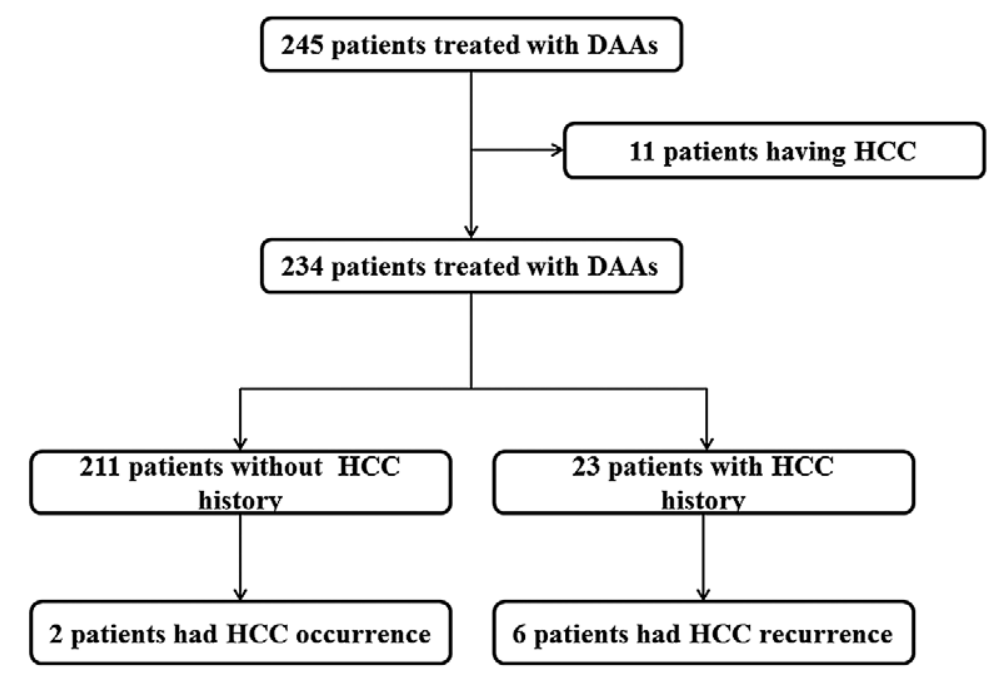

Fig. 1. Flow chart of study population.Eleven patients treated with direct-acting antivirals (DAAs) were excluded. This was due to the presence of potential HCC nodules according to second opinion based on evidence from ultrasonography (US), computed tomography (CT), or magnetic resonance imaging (MRI) before DAA treatment 
Table I. Baseline characteristics of patients according to the study group

\begin{tabular}{|c|c|c|c|}
\hline Characteristics & $\begin{array}{l}\text { All patients } \\
(\mathrm{n}=234)\end{array}$ & $\begin{array}{l}\text { No-HCC-history } \\
\text { group }(n=211)\end{array}$ & $\begin{array}{l}\text { HCC-history } \\
\text { group }(\mathrm{n}=23)\end{array}$ \\
\hline Age, years (median, range) & $65(27-88)$ & $63(27-88)$ & $75(55-88)$ \\
\hline Male sex, n (\%) & $123(52.5)$ & $109(51.7)$ & $14(60.9)$ \\
\hline \multicolumn{4}{|l|}{ HCV genotype } \\
\hline $1 \mathrm{a} / 1 \mathrm{~b} / 2 \mathrm{a} / 2 \mathrm{~b}$ & $3 / 174 / 39 / 18$ & $3 / 156 / 36 / 16$ & $0 / 18 / 3 / 2$ \\
\hline \multicolumn{4}{|l|}{ Treatment regimen } \\
\hline $\mathrm{DCV}+\mathrm{ASV}$ & 65 & 58 & 7 \\
\hline SOF / LDV & 77 & 70 & 7 \\
\hline $\mathrm{OBV} / \mathrm{PTV} / \mathrm{r}$ & 24 & 23 & 1 \\
\hline $\mathrm{EBR}+\mathrm{GZR}$ & 11 & 8 & 3 \\
\hline $\mathrm{SOF}+\mathrm{RBV}$ & 57 & 52 & 5 \\
\hline No. of treatments for HCC & $1(1-8)$ & None & $1(1-8)$ \\
\hline Observation period (months) & $21(6-38)$ & $21(6-38)$ & $15(6-35)$ \\
\hline
\end{tabular}

HCV: hepatitis C virus; DCV: daclatasvir; ASV: asunaprevir; SOF: sofosbuvir; LDV: ledipasvir; OBV: ombitasvir; PTV: pibrentasvir; r: ritonavir; EBR: elbasvir; GZR: grazoprevir; RBV: ribavirin; HCC: hepatocellular carcinoma.

\section{RESULTS}

Cumulative occurrence- and recurrence-free rates of HCC after DAA treatment

All patients were observed for at least 6 months after DAA treatment. Of the total number of patients (234), SVR24 was achieved in 214 (91.5\%) (Fig. 2).

SVR24 rate in all patients $=91.5 \%(n=234)$

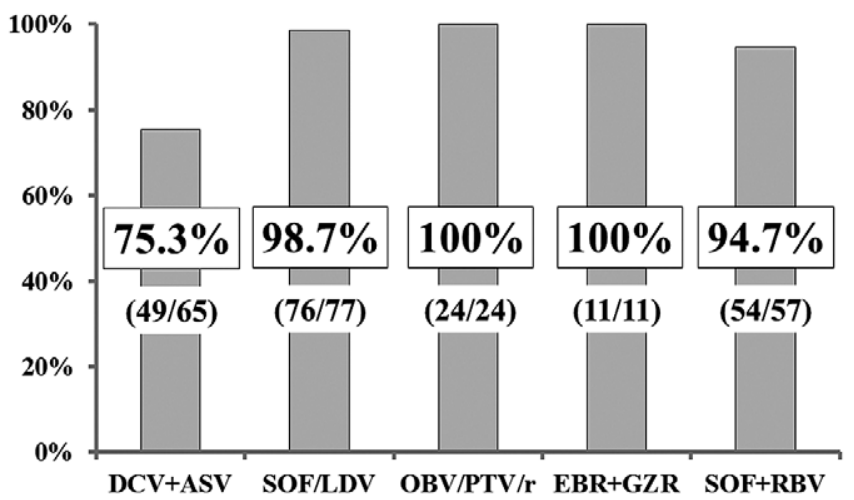

Fig. 2. SVR2 4 rates after DAA treatment. All patients were observed for at least 6 months after DAA treatment. Among the 234 patients, sustained virological response (SVR24) was achieved in 214 (91.5\%). DCV: daclatasvir; ASV: asunaprevir; SOF: sofosbuvir; LDV: ledipasvir; OBV: ombitasvir; PTV: pibrentasvir; r: ritonavir; EBR: elbasvir; GZR: grazoprevir; RBV: ribavirin.

In the no-HCC-history group, HCC occurred in two patients (Fig. 1). In the HCC-history group, HCC recurred in six. In the no-HCC-history group, the 1- and 3-year occurrencefree rates of HCC were $100 \%$ and $98.8 \%$, respectively. In the HCC-history group, the 1- and 3-year recurrence-free rates were $87.0 \%$ and $64.6 \%$, respectively. A significant difference was observed between the two groups ( $<<0.0001$ ) (Fig. 3).

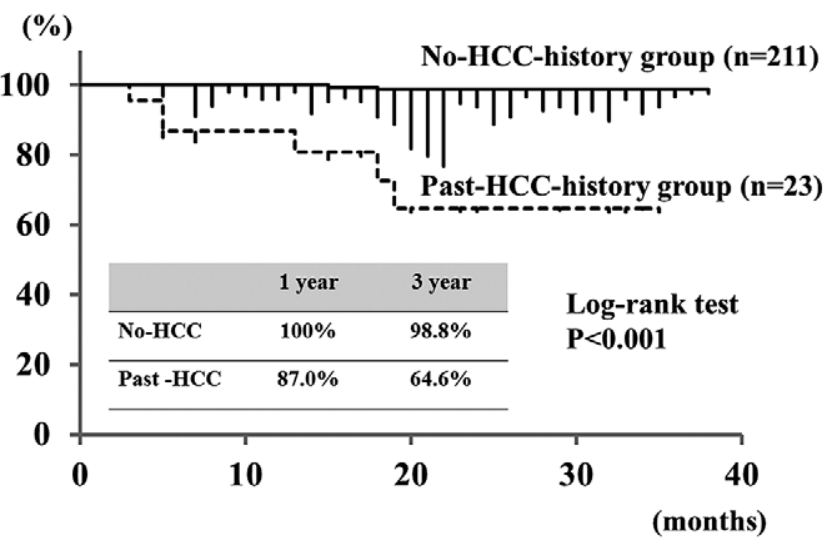

Fig. 3. Cumulative occurrence-free (recurrence-free) rates of HCC One- and 3-year occurrence-free rates of HCC were $100 \%$ and $98.8 \%$, respectively, in no-HCC-history group; recurrence-free rates were $87.0 \%$ and $64.6 \%$, respectively, in HCC-history group. A significant difference was observed between the two groups for occurrence or recurrence $(\mathrm{p}<0.0001)$.

Factors associated with HCC occurrence or recurrence

The patients were divided into two groups: no HCC after DAAs group and HCC after DAAs group. Factors associated with occurrence or recurrence of HCC were then analyzed (Table II). Univariate analysis with the Mann-Whitney U-test revealed platelet count, albumin level, a-fetoprotein (AFP) level, AFP-L3\%, the fibrosis-4 (FIB-4) index score, and the AST-to-Platelet Ratio Index (APRI) score before DAA treatment, and the platelet count, albumin level, AFP level, AFP-L3\%, FIB-4 index score, and APRI after DAA treatment as factors showing a significant difference between the two groups. No significant differences were observed, however, for body mass index score, history of diabetes mellitus, alcoholism, or HCV genotype. Multivariate analysis with Cox proportional hazards revealed that AFP level before DAA treatment, and AFP level and AFP-L3\% after DAA treatment as factors independently associated with HCC development. 
Table II. Factors related to HCC occurrence or recurrence in all DAAs treated patients.

\begin{tabular}{|c|c|c|c|c|}
\hline Characteristics & $\begin{array}{l}\text { No HCC after DAAs } \\
\qquad(\mathrm{n}=226)\end{array}$ & $\begin{array}{l}\text { HCC after DAAs } \\
(\mathrm{n}=8)\end{array}$ & $\begin{array}{l}\text { Mann-Whitney } \\
\text { U-test p-value }\end{array}$ & $\begin{array}{l}\text { Cox proportional } \\
\text { hazards p-value }\end{array}$ \\
\hline Age, years (median, range) & $65(27-88)$ & $70(55-80)$ & 0.76 & \\
\hline Male sex, n (\%) & $117(51.8)$ & $6(75.0)$ & $0.20^{\dagger}$ & \\
\hline BMI $\left(\mathrm{kg} / \mathrm{m}^{2}\right)$ & $22.2(12.7-37.2)$ & $23.3(18.2-26.4)$ & 0.63 & \\
\hline Diabetes mellitus, n (\%) & $30(13.2)$ & $2(25.0)$ & $0.34^{\dagger}$ & \\
\hline Alcoholism, n (\%) & $14(6.2)$ & $0(0)$ & $0.47^{\dagger}$ & \\
\hline HCV genotype $1 \mathrm{a} / 1 \mathrm{~b} / 2 \mathrm{a} / 2 \mathrm{~b}$ & $3 / 167 / 39 / 17$ & $0 / 7 / 0 / 1$ & $0.59^{\dagger}$ & \\
\hline SVR24, n (\%) & $207(91.6)$ & $7(87.5)$ & 0.68 & \\
\hline \multicolumn{5}{|l|}{ Blood test results - before DAA } \\
\hline Platelets $\left(\times 10^{4} / \mu \mathrm{L}\right)$ & $16.0(2.9-50.0)$ & $8.8(2.8-20.6)$ & 0.011 & 0.89 \\
\hline AST (IU/L) & $44(13-266)$ & $61(22-90)$ & 0.35 & \\
\hline ALT (IU/L) & $42.5(10-658)$ & $56(20-134)$ & 0.57 & \\
\hline Total bilirubin (mg/dL) & $0.65(0.18-2.35)$ & $0.59(0.43-0.96)$ & 0.80 & \\
\hline $\operatorname{Albumin}(\mathrm{g} / \mathrm{dL})$ & $4.0(2.5-4.8)$ & $3.6(3.2-4.0)$ & 0.003 & 0.11 \\
\hline $\operatorname{AFP}(\mathrm{ng} / \mathrm{mL})$ & $4.5(1.0-247.4)$ & $10.1(3.7-322.3)$ & 0.020 & 0.045 \\
\hline AFP-L3 (\%) & $0.5(0.5-25.7)$ & $2.05(0.5-23.0)$ & 0.0048 & 0.67 \\
\hline PIVKA2 (mAU/mL) & $17(7-148)$ & $16.5(12-28)$ & 0.35 & \\
\hline FIB-4 index & $2.9(0.5-16.4)$ & $5.7(1.9-18.5)$ & 0.011 & 0.64 \\
\hline APRI & $0.8(0.1-7.1)$ & $1.6(0.3-6.6)$ & 0.040 & 0.41 \\
\hline \multicolumn{5}{|l|}{ Blood test results - after DAA } \\
\hline Platelets $\left(\times 10^{4} / \mu \mathrm{L}\right)$ & $17.3(3.0-61.3)$ & $8.0(3.4-20.9)$ & 0.0062 & 0.86 \\
\hline AST (IU/L) & $23(9-132)$ & $31(14-86)$ & 0.24 & \\
\hline ALT (IU/L) & $16(5-175)$ & $25(9-134)$ & 0.36 & \\
\hline Total bilirubin (mg/dL) & $0.66(0.1-2.15)$ & $0.57(0.5-1.23)$ & 0.78 & \\
\hline Albumin (g/dL) & $4.2(2.9-4.9)$ & $3.9(3.6-4.1)$ & 0.0075 & 0.14 \\
\hline $\operatorname{AFP}(\mathrm{ng} / \mathrm{mL})$ & $3.3(0.8-174.7)$ & $7.0(2-8452.2)$ & 0.030 & 0.043 \\
\hline AFP-L3 (\%) & $0.5(0.5-30.9)$ & $11.0(0.5-47.7)$ & $<0.0001$ & 0.005 \\
\hline PIVKA2 (mAU/mL) & $19(1.8-93)$ & $21(13-45)$ & 0.56 & \\
\hline FIB-4 index & $2.2(0.4-14.3)$ & $5.6(1.6-12.3)$ & 0.0048 & 0.98 \\
\hline APRI & $0.4(0.1-3.4)$ & $0.9(0.2-3.3)$ & 0.019 & 0.27 \\
\hline Liver stiffness $(\mathrm{kPa}, \mathrm{n}=69)$ & $10.3(4.2-25.6, \mathrm{n}=6)$ & $16(11-42.8, \mathrm{n}=63)$ & 0.025 & \\
\hline
\end{tabular}

Data are expressed as median value, range, and percentage. Mann-Whitney U-test was used to compare values as univariate analysis. Cox proportional hazard regression analysis was performed as multivariate analysis. ${ }^{\dagger}$ Differences for each characteristic were tested using chi-squared test. A p-value of $<0.05$ was considered to indicate statistically significant difference. SVR: sustained virological response; DAAs: direct acting antivirals; AST: aspartate aminotransferase; ALT: alanine aminotransferase; AFP: alpha-fetoprotein; PIVKA2: protein induced by Vitamin K absence or antagonists-I2; FIB-4: fibrosis-4; APRI: AST to Platelet Ratio Index.

In the no-HCC-history group, total bilirubin, albumin, AST level, and AFP-L3\% after DAA treatment were found to be significant factors by univariate analysis. No significant factors were found by multivariate analysis, however (Table III).

In the HCC-history group, AFP L3\% after DAA treatment was found to be associated with recurrence of HCC by univariate analysis, and a possible predictor of HCC recurrence by multivariate analysis $(\mathrm{p}=0.066)($ Table IV). One case was local recurrence and five were multicentric carcinogenesis (Table IV).

The SVR24 rate showed no significant association with a decrease in the incidence of HCC in any group.

\section{Effect of DAAs on liver function}

The effect of DAAs on liver function was investigated by comparing the blood examination values obtained before and 24 months after DAA treatment. Platelet count, AST, ALT, albumin, AFP, FIB-4 index score, and the APRI score showed a significant improvement after DAA treatment (Table V).

\section{Liver stiffness and HCC incidence}

Liver stiffness was determined by ultrasound elastography in 69 out of the total number of 234 patients before DAA administration. Hepatocellular carcinoma occurred in 6 patients. A significant difference was observed in the median liver stiffness value between the no-HCC-history group and 
Table III. Factors related to HCC occurrence in no-HCC-history patients

\begin{tabular}{|c|c|c|c|c|}
\hline Characteristics & $\begin{array}{c}\text { No HCC occurrence } \\
(\mathrm{n}=209)\end{array}$ & $\begin{array}{l}\text { HCC occurrence } \\
(\mathrm{n}=2)\end{array}$ & $\begin{array}{l}\text { Mann-Whitney } \\
\text { U-test p-value }\end{array}$ & $\begin{array}{c}\text { Cox proportiona } \\
\text { hazardsp-value }\end{array}$ \\
\hline Age, years (median, range) & $63(27-88)$ & $68.5(67-70)$ & 0.44 & \\
\hline Male sex, n (\%) & $107(51.2)$ & $2(100)$ & $0.17^{\dagger}$ & \\
\hline $\operatorname{BMI}\left(\mathrm{kg} / \mathrm{m}^{2}\right)$ & $22.2(12.7-37.2)$ & $25.4(24.3-26.4)$ & 0.11 & \\
\hline Diabetes mellitus, $\mathrm{n}(\%)$ & $28(13.4)$ & $0(0)$ & $0.58 \dagger$ & \\
\hline Alcoholism, n (\%) & $13(6.2)$ & $0(0)$ & $0.72^{\dagger}$ & \\
\hline HCV genotype $1 \mathrm{a} / 1 \mathrm{~b} / 2 \mathrm{a} / 2 \mathrm{~b}$ & $3 / 154 / 36 / 16$ & $0 / 2 / 0 / 0$ & $0.87^{\dagger}$ & \\
\hline SVR24, n (\%) & $192(91.9)$ & $2(100)$ & 0.67 & \\
\hline \multicolumn{5}{|l|}{ Blood test results - before DAA } \\
\hline Platelets $\left(\times 10^{4} / \mu \mathrm{L}\right)$ & $16.9(2.9-50.0)$ & $13.8(9.8-17.7)$ & 0.48 & \\
\hline AST (IU/L) & $43(13-266)$ & $73.5(57-90)$ & 0.22 & \\
\hline $\operatorname{ALT}(\mathrm{IU} / \mathrm{L})$ & $43(10-658)$ & $90.5(57-124)$ & 0.27 & \\
\hline Total bilirubin (mg/dL) & $0.63(0.18-2.35)$ & $0.77(0.62-0.92)$ & 0.029 & 0.85 \\
\hline Albumin (g/dL) & $4.1(2.5-4.8)$ & $3.6(3.5-3.7)$ & $<0.001$ & 0.57 \\
\hline $\operatorname{AFP}(\mathrm{ng} / \mathrm{mL})$ & $4.4(1.0-247.4)$ & $8.5(5.9-11.0)$ & 0.27 & \\
\hline AFP-L3 (\%) & $0.5(0.5-9.3)$ & $0.5(0.5-0.5)$ & 0.58 & \\
\hline PIVKA2 (mAU/mL) & $17.5(8-148)$ & $15(12-18)$ & 0.36 & \\
\hline FIB-4 index & $2.7(0.5-16.4)$ & $4.2(3.2-5.2)$ & 0.33 & \\
\hline APRI & $0.8(0.1-7.1)$ & $1.4(1.3-1.5)$ & 0.22 & \\
\hline \multicolumn{5}{|l|}{ Blood test results - after DAA } \\
\hline Platelets $\left(\times 10^{4} / \mu \mathrm{L}\right)$ & $17.6(3.0-61.3)$ & $13.9(7.7-20.0)$ & 0.47 & \\
\hline AST (IU/L) & $23(9-132)$ & $35(29-41)$ & 0.0027 & 0.62 \\
\hline $\operatorname{ALT}(\mathrm{IU} / \mathrm{L})$ & $16(5-175)$ & $31.5(30-33)$ & 0.10 & \\
\hline Total bilirubin (mg/dL) & $0.66(0.1-2.15)$ & $0.92(0.6-1.23)$ & 0.36 & \\
\hline Albumin $(\mathrm{g} / \mathrm{dL})$ & $4.2(2.9-4.9)$ & $3.9(3.8-4.0)$ & 0.39 & \\
\hline $\operatorname{AFP}(\mathrm{ng} / \mathrm{mL})$ & $3.2(0.8-174.7)$ & $6.7(4.6-8.8)$ & 0.083 & \\
\hline AFP-L3 (\%) & $0.5(0.5-4.8)$ & $31.5(15.2-47.7)$ & $<0.0001$ & 0.13 \\
\hline PIVKA2 (mAU/mL) & $19(1.8-93)$ & $23.5(20-27)$ & 0.26 & \\
\hline FIB-4 index & $2.1(0.4-14.3)$ & $4.0(1.9-6.2)$ & 0.31 & \\
\hline APRI & $0.4(0.1-3.4)$ & $0.9(0.4-1.4)$ & 0.20 & \\
\hline Liver stiffness $(\mathrm{kPa}, \mathrm{n}=60)$ & $10.0(4.2-25.6, \mathrm{n}=59)$ & $16.7(16.7, \mathrm{n}=1)$ & 0.42 & \\
\hline
\end{tabular}

Data are expressed as median value, range, and percentage. Mann-Whitney U-test was used to compare values as univariate analysis. Cox proportional hazard regression analysis was performed as multivariate analysis. ${ }^{\dagger}$ Differences for each characteristic were tested using chi-squared test. A p-value of $<0.05$ was considered to indicate statistically significant difference. For abbreviations see Table II.

the HCC-occurrence and recurrence group (Table II). When limited to the no-HCC-history group, however, liver stiffness was not found to be a specific factor associated with HCC incidence (Table III).

Liver stiffness was measured at the time of SVR24 in 85 patients. Measurement of liver stiffness both before and after administration of DAAs was possible in only 50 patients, however. In this group, liver stiffness was compared between before and after administration of DAAs. The median value for liver stiffness after DAAs showed a significant decrease (from 10.9 to $7.8 \mathrm{kPa}$ ) (Table V).

\section{DISCUSSION}

Administration of DAAs eradicated HCV in more than $90 \%$ of patients in this study (Fig. 2), even in those who were elderly or in whom cirrhosis had progressed. The most important point is whether elimination of $\mathrm{HCV}$ can reduce liver disease-related death, which is strongly affected by the incidence of HCC. The incidence of HCC after SVR involves two concepts: missed HCC on imaging and new incidence. To exclude missed HCC, all images obtained by US, CT, or MRI in our patients were repeatedly reviewed. Hepatocellular carcinoma was found in 11 patients before starting DAAs treatment. These patients were excluded from the study (Fig. 1). The SVR24 rate was lower in the DCV + ASV group than in the other groups. This might have been because three of these patients harbored a mutation in the $\mathrm{Y} 93 \mathrm{H}$ region. This was not investigated in this study, however, so this remains open to doubt. Moreover, medication was interrupted by drug-induced liver injury in another three cases, which also might have skewed the results.

Earlier studies have shown that IFN reduced the incidence of HCC through immune activation and antitumor effects. It was found that the 3 - and 5-year cumulative incidence of HCC 
Table IV. Factors related to HCC recurrence in HCC-history patients

\begin{tabular}{|c|c|c|c|c|}
\hline Characteristics & $\begin{array}{c}\text { No HCC recurrence } \\
(\mathrm{n}=17)\end{array}$ & $\begin{array}{l}\text { HCC recurrence } \\
\quad(n=6)\end{array}$ & $\begin{array}{c}\text { Mann-Whitney U-test } \\
\text { p-value }\end{array}$ & $\begin{array}{l}\text { Cox proportional } \\
\text { hazards p-value }\end{array}$ \\
\hline Age, years (median, range) & $75(65-88)$ & $73.5(55-80)$ & 0.36 & \\
\hline Male sex, n (\%) & $10(58.8)$ & $4(66.7)$ & $0.74^{\dagger}$ & \\
\hline BMI $\left(\mathrm{kg} / \mathrm{m}^{2}\right)$ & $22.5(14.9-27.9)$ & $21.9(18.2-25.8)$ & 0.89 & \\
\hline Diabetes mellitus, n (\%) & $2(11.8)$ & $2(33.3)$ & $0.23^{\dagger}$ & \\
\hline Alcoholism, n (\%) & $1(5.9)$ & $0(0)$ & $0.54^{\dagger}$ & \\
\hline HCV genotype $1 \mathrm{a} / 1 \mathrm{~b} / 2 \mathrm{a} / 2 \mathrm{~b}$ & $0 / 13 / 3 / 1$ & $0 / 5 / 0 / 1$ & $0.64^{\dagger}$ & \\
\hline SVR24, n (\%) & $15(88.2)$ & $5(83.3)$ & 0.76 & \\
\hline Type of recurrence (Local / Multicentric) & NA & $1 / 5$ & & \\
\hline \multicolumn{5}{|l|}{ Blood test results - before DAA } \\
\hline Platelets $\left(\times 10^{4} / \mu \mathrm{L}\right)$ & $10.3(5.6-20.7)$ & $8.0(2.8-20.6)$ & 0.21 & \\
\hline AST (IU/L) & $50(21-119)$ & $56(22-86)$ & 0.86 & \\
\hline $\operatorname{ALT}(\mathrm{IU} / \mathrm{L})$ & $42(15-179)$ & $42(20-134)$ & 0.92 & \\
\hline Total bilirubin $(\mathrm{mg} / \mathrm{dL})$ & $0.69(0.28-1.42)$ & $0.55(0.43-0.96)$ & 0.20 & \\
\hline $\operatorname{Albumin}(\mathrm{g} / \mathrm{dL})$ & $3.5(3.1-4.2)$ & $3.6(3.2-4.0)$ & 0.86 & \\
\hline $\operatorname{AFP}(n g / m L)$ & $8.1(2.4-50.7)$ & $12.6(3.7-322.3)$ & 0.18 & \\
\hline AFP-L3 (\%) & $2.6(0.5-25.7)$ & $7.1(0.5-23.0)$ & 0.27 & \\
\hline PIVKA2 (mAU/mL) & $17.0(7-78)$ & $16.5(12-28)$ & 0.86 & \\
\hline FIB-4 index & $6.7(3.0-11.3)$ & $6.5(1.9-18.5)$ & 0.78 & \\
\hline APRI & $1.8(0.5-3.4)$ & $1.7(0.3-6.6)$ & 0.72 & \\
\hline \multicolumn{5}{|l|}{ Blood test results - after DAA } \\
\hline Platelets $\left(\times 10^{4} / \mu \mathrm{L}\right)$ & $11.2(6.0-20.2)$ & $7.9(3.4-20.9)$ & 0.079 & \\
\hline AST (IU/L) & $32(14-85)$ & $28.5(14-86)$ & 0.73 & \\
\hline ALT (IU/L) & $18(7-88)$ & $16.5(9-134)$ & 0.94 & \\
\hline Total bilirubin $(\mathrm{mg} / \mathrm{dL})$ & $0.85(0.17-1.28)$ & $0.52(0.48-1.1)$ & 0.080 & \\
\hline Albumin $(\mathrm{g} / \mathrm{dL})$ & $3.9(3.0-4.6)$ & $3.9(3.6-4.1)$ & 0.72 & \\
\hline $\operatorname{AFP}(\mathrm{ng} / \mathrm{mL})$ & $5.4(1.4-8.8)$ & $8.2(2-452.2)$ & 0.39 & \\
\hline AFP-L3 (\%) & $0.5(0.5-30.9)$ & $5.6(0.5-36.0)$ & 0.0026 & 0.066 \\
\hline PIVKA2 (mAU/mL) & $19(10-73)$ & $19(13-45)$ & 0.91 & \\
\hline FIB-4 index & $5.4(2.0-8.9)$ & $6.0(1.6-12.3)$ & 0.48 & \\
\hline APRI & $0.7(0.3-2.4)$ & $0.9(0.2-3.3)$ & 0.42 & \\
\hline Liver stiffness $(\mathrm{kPa}, \mathrm{n}=9)$ & $12.7(12-16.8, \mathrm{n}=5)$ & $15.3(11-42.8, \mathrm{n}=4)$ & 0.39 & \\
\hline
\end{tabular}

Data are expressed as median value, range, and percentage. Mann-Whitney U-test was used to compare values as univariate analysis. Cox proportional hazard regression analysis was performed as multivariate analysis. ${ }^{\dagger}$ Differences for each characteristic were tested using chisquared test. A p-value of $<0.05$ was considered to indicate statistically significant difference. For abbreviations see Table II.

in CHC patients was approximately $1 \%$ and $2 \%$, respectively, after IFN-induced SVR [5, 7]. In elderly or cirrhotic patients, however, these rates were observed to deteriorate, even after SVR. In patients aged over 65 years, the 5-year cumulative incidence was reported to be $6 \%$ [8]. In another report, the 5 -year cumulative incidence in cirrhotic patients was very high (18.9\%), even after IFN-induced SVR [9]. Treatment with DAAs enables elimination of HCV with a high SVR rate in patients with advanced age or severe fibrosis, which are high risks for HCC. Therefore, it is very important to clarify how treatment with DAAs affects the incidence of HCC and to determine the predictive factors. In the present study, the 1 - and 3-year cumulative occurrence rate of $\mathrm{HCC}$ was $0 \%$ and $1.2 \%$, respectively. A comparison was made with the results of earlier studies using IFN as a historical control. Chang et al. [10] showed that combination therapy with pegylated IFN and ribavirin prevented the occurrence of HCC in $871 \mathrm{CHC}$ patients. In their report, the 3-year cumulative occurrence rate of HCC was $1.2 \%$. This finding is supported by the present results, which showed the same level after DAAs. Another report showed that the 5-year cumulative occurrence rate in $\mathrm{HCV}$-infected patients without HCV treatment was $11.8 \%$, which was very high compared with the treatment group [11]. Taken together with our findings, this indicates that DAAs exert a suppressive effect on the incidence of HCC similar to that of IFN.

Regarding the suppressive effect of DAAs on recurrence of HCC in the present study, the 1-, 2-, and 3-year cumulative recurrence rate of HCC in the HCC-history group was $13.0 \%$, $35.4 \%$, and $35.4 \%$, respectively. This result was compared with that of an earlier report as a historical control. Minami et al. [12] found that the 1-, 2-, and 3-year cumulative recurrence 
Table V. Effect of DAAs on liver function

\begin{tabular}{|c|c|c|c|}
\hline Characteristics $(\mathrm{n}=234)$ & Before DAA & After DAA & $\begin{array}{l}\text { Wilcoxon signed } \\
\text { rank test p-value }\end{array}$ \\
\hline Platelets $\left(\times 10^{4} / \mu \mathrm{L}\right)$ & $15.9(2.8-50.0)$ & $17.0(3.0-61.3)$ & $<0.0001$ \\
\hline AST (IU/L) & $45(13-266)$ & $23(9-132)$ & $<0.0001$ \\
\hline $\operatorname{ALT}(\mathrm{IU} / \mathrm{L})$ & $43(10-658)$ & $16(5-175)$ & $<0.0001$ \\
\hline Total bilirubin (mg/dL) & $0.64(0.18-2.35)$ & $0.66(0.1-2.15)$ & 0.59 \\
\hline Albumin (g/dL) & $4.0(2.5-4.8)$ & $4.2(2.9-4.9)$ & $<0.0001$ \\
\hline $\operatorname{AFP}(\mathrm{ng} / \mathrm{mL})$ & $4.6(1.0-322.3)$ & $3.3(0.8-452.2)$ & $<0.0001$ \\
\hline AFP-L3 (\%) & $0.5(0.5-25.7)$ & $0.5(0.5-47.7)$ & 0.0021 \\
\hline PIVKA2 (mAU/mL) & $17(7-148)$ & $19(1.8-93)$ & 0.49 \\
\hline FIB-4 index & $3.0(0.5-18.5)$ & $2.2(0.4-14.3)$ & $<0.0001$ \\
\hline APRI & $0.9(0.1-7.1)$ & $0.3(0.1-3.4)$ & $<0.0001$ \\
\hline Liver stiffness $(\mathrm{kPa}, \mathrm{n}=50)$ & $10.9(4.4-34.8)$ & $7.8(4.4-20.5)$ & $<0.0001$ \\
\hline
\end{tabular}

rates of HCC after IFN-SVR were $26.3 \%, 52.9 \%$, and more than $60 \%$, respectively. This recurrence rate after IFN-treatment is much worse than that observed here. Ikeda et al. [13] found that the crude recurrence rate was approximately $50 \%$ at the 3rd year after HCC treatment in non-antiviral therapy patients. Thus, the 3-year recurrence rate observed in the present study was better than those seen in these earlier reports. One metaanalysis showed that the HCC recurrence rate/100-person years after IFN-SVR was $9.2 \%$ and that after DAA-SVR was $12.1 \%$ [14]. These results are comparable with the 1-year cumulative HCC recurrence rate of $13.0 \%$ found in the present study. Thus, DAAs also appear to suppress recurrence of HCC similarly to IFN. The recurrence rate of HCC in this study was superior to that after IFN-SVR. It has been reported that fewer past treatments for HCC lead to a lower rate of recurrence rate [13]. We believe that the lower recurrence rate of HCC observed in the present study was a result of fewer past treatments for HCC (Table I).

Further studies are required to identify the factors related to the incidence of HCC after DAAs treatment. In the present study, many factors were extracted by univariate analysis (Table II), and they were almost the same as those related to the incidence of HCC after IFN-SVR reported previously [15, 16]. The present multivariate analysis revealed that the AFP values before and after DAA treatment and AFP-L3\% after DAA treatment were independently related to the occurence/ recurrence of HCC (Table II). Recently, some studies showed that high AFP value at the end of DAA treatment was a predictor of HCC occurrence [17] or recurrence [18-20] in the multivariate analysis. Interestingly, there was only one study showing that AFP value before DAA treatment was a predictor of HCC recurrence [21]. AFP value decreases after DAA treatment in many cases. Therefore, continuous high AFP value even after DAA treatment seemed to be the predictor in the studies mentioned above. However, AFP value before DAA treatment might also be strongly related with HCC incidence according to our results and careful monitoring for AFP value should be performed. To our knowledge, no previous studies have reported an association between the AFP L3\% and incidence of HCC after DAAs. Our results are very important also in this point. In the present subgroup analysis (no-HCChistory and HCC-history groups), AFP was not identified as an independent factor because the observation period was relatively short. Moreover, the SVR rate after DAA treatment was not identified as an independent factor for apparently the same reason. However, the AFP L3\% after DAA treatment was the predictor of HCC occurrence and recurrence in our univariate analysis. In the multivariate analysis as well, AFP L3\% was close to be a predictor of HCC recurrence $(p=0.063)$ (Table IV).

Most liver function values according to blood tests improved after DAA treatment. Liver stiffness also showed a significant decrease (Table V). Liver stiffness on ultrasound elastography was determined by acoustic radiation force impulse (ARFI) and shear wave techniques $[22,23]$. Liver elasticity is influenced by diffuse fibrosis, congestion, inflammation $[24,25]$ and jaundice $[26,27]$. Liver congestion is induced by portal hypertension or immune cell infiltration. It has not been proved that DAA treatment can decrease portal venous pressure in a short period within 3 months. Therefore, DAA treatment appears to improve liver inflammation immediately. Long-term observation of liver stiffness to determine the effects of DAA treatment on fibrosis and portal hypertension is required.

This study has some limitations. The study was carried out at a single institution and the patient sample was relatively small.

\section{CONCLUSIONS}

Our study confirmed that DAAs decrease HCC occurrence and recurrence. It also showed that AFP or AFP-L3\% were the predictors of HCC incidence after DAAs. A further, multicenter prospective study is now being planned for the near future.

Conflicts of interest: None declared. 
Authors' contributions: Y.Y. drafted the manuscript and collected data. Y.F. designed the study drafted the manuscript and collected data and created the figures. Y.K. collected data, managed the patients and reviewed the imaging examinations. H.T. managed the patients and reviewed the imaging examinations. K.S. reviewed the imaging examinations and performed the statistical analysis. I.N. suggested the study concept. T.I. recruited the patient.

Financial support: This study was partly supported by a Health and Labour Sciences Research Grant from the Japanese Ministry of Health, Labour and Welfare for Research on Intractable Diseases and Portal Hemodynamic Abnormalities.

Acknowledgements: We would like to thank Professor Jeremy Williams from the Department of International Medical Communications at Tokyo Medical University for his editorial assistance with English for this manuscript.

\section{REFERENCES}

1. Thein HH, Yi Q, Dore GJ, Krahn MD. Estimation of stage-specific fibrosis progression rates in chronic hepatitis $\mathrm{C}$ virus infection: a meta-analysis and meta-regression. Hepatology 2008;48:418-431. doi:10.1002/hep.22375

2. Sangiovanni A, Del Ninno E, Fasani P, et al. Increased survival of cirrhotic patients with a hepatocellular carcinoma detected during surveillance. Gastroenterology 2004;126:1005-1014. doi:10.1053/j. gastro.2003.12.049

3. Morgan RL, Baack B, Smith BD, Yartel A, Pitasi M, Falck-Ytter Y. Eradication of hepatitis $C$ virus infection and the development of hepatocellular carcinoma: a meta-analysis of observational studies. Ann Intern Med 2013;158:329-337. doi:10.7326/0003-4819-158-5201303050-00005

4. Nahon P, Bourcier V, Layese R, et al. Eradication of Hepatitis C Virus infection in patients with cirrhosis reduces risk of liver and non-liver complications. Gastroenterology 2017;152:142-156.e2. doi:10.1053/j. gastro.2016.09.009

5. Hiramatsu N, Oze T, Takehara T. Suppression of hepatocellular carcinoma development in hepatitis $\mathrm{C}$ patients given interferon-based antiviral therapy. Hepatol Res 2015;45:152-161. doi:10.1111/hepr.12393

6. Reig M, Mariño Z, Perelló C, et al. Unexpected high rate of early tumor recurrence in patients with HCV-related HCC undergoing interferonfree therapy. J Hepatol 2016;65:719-726. doi:10.1016/j.jhep.2016.04.008

7. Conti F, Buonfiglioli F, Scuteri A, et al. Early occurrence and recurrence of hepatocellular carcinoma in HCV-related cirrhosis treated with direct-acting antivirals. J Hepatol 2016;65:727-733. doi:10.1016/j. jhep.2016.06.015

8. Asahina $\mathrm{Y}$, Tsuchiya $\mathrm{K}$, Tamaki N, et al. Effect of aging on risk for hepatocellular carcinoma in chronic hepatitis $\mathrm{C}$ virus infection. Hepatology 2010;52:518-527. doi:10.1002/hep.23691

9. Ogawa E, Furusyo N, Kajiwara E, et al. Efficacy of pegylated interferon alpha- $2 \mathrm{~b}$ and ribavirin treatment on the risk of hepatocellular carcinoma in patients with chronic hepatitis C: a prospective, multicenter study. J Hepatol 2013;58:495-501. doi:10.1016/j.jhep.2012.10.017

10. Chang KC, Hung $\mathrm{CH}, \mathrm{Lu} \mathrm{SN}$, et al. A novel predictive score for hepatocellular carcinoma development in patients with chronic hepatitis $\mathrm{C}$ after sustained response to pegylated interferon and ribavirin combination therapy. J Antimicrob Chemother 2012;67:2766-2772. doi:10.1093/jac/dks269
11. Tateyama M, Yatsuhashi H, Taura N, et al. Alpha-fetoprotein above normal levels as a risk factor for the development of hepatocellular carcinoma in patients infected with hepatitis C virus. J Gastroenterol 2011;46:92-100. doi:10.1007/s00535-010-0293-6

12. Minami T, Tateishi R, Nakagomi R, et al. The impact of direct-acting antivirals on early tumor recurrence after radiofrequency ablation in hepatitis C-related hepatocellular carcinoma. J Hepatol 2016;65:12721273. doi:10.1016/j.jhep.2016.07.043

13. Ikeda K, Kawamura Y, Kobayashi M, et al. Direct-acting antivirals decreased tumor recurrence after initial treatment of hepatitis C virus-related hepatocellular carcinoma. Dig Dis Sci 2017;62:2932-2942. doi:10.1007/s10620-017-4739-z

14. Waziry R, Hajarizadeh B, Grebely J, et al. Hepatocellular carcinoma risk following direct-acting antiviral HCV therapy: A systematic review, meta-analyses, and meta-regression. J Hepatol 2017;67:1204-1212. doi:10.1016/j.jhep.2017.07.025

15. Lok AS, Seeff LB, Morgan TR, et al; HALT-C Trial Group. Incidence of hepatocellular carcinoma and associated risk factors in hepatitis C-related advanced liver disease. Gastroenterology 2009;136:138-148. doi:10.1053/j.gastro.2008.09.014

16. ANRS collaborative study group on hepatocellular carcinoma (ANRS CO22 HEPATHER, CO12 CirVir and CO23 CUPILT cohorts). Lack of evidence of an effect of direct-acting antivirals on the recurrence of hepatocellular carcinoma: Data from three ANRS cohorts. J Hepatol 2016;65:734-740. doi:10.1016/j.jhep.2016.05.045

17. Watanabe T, Tokumoto Y, Joko K, et al. Predictors of hepatocellular carcinoma occurrence after direct-acting antiviral therapy in patients with hepatitis C virus infection. Hepatol Res 2019;49:136-146. doi:10.1111/hepr.13278

18. Yasui $\mathrm{Y}$, Kurosaki M, Komiyama Y, et al. Wisteria floribunda agglutinin-positive Mac-2 binding protein predicts early occurrence of hepatocellular carcinoma after sustained virologic response by directacting antivirals for hepatitis C virus. Hepatol Res 2018;48:1131-1139. doi:10.1111/hepr.13233

19. Kwon JH, Yoo SH, Nam SW, et al. Clinical outcomes after the introduction of direct antiviral agents for patients infected with genotype $1 \mathrm{~b}$ hepatitis $\mathrm{C}$ virus depending on the regimens: A multicenter study in Korea. J Med Virol 2019 Jan 29. doi:10.1002/jmv.25412

20. Mashiba T, Joko K, Kurosaki M, et al. Does interferon-free directacting antiviral therapy for hepatitis $\mathrm{C}$ after curative treatment for hepatocellular carcinoma lead to unexpected recurrences of HCC? A multicenter study by the Japanese Red Cross Hospital Liver Study Group. PLoS One 2018;13:e0194704. doi:10.1371/journal.pone.0194704

21. Lleo A, Aglitti A, Aghemo A, et al. Predictors of hepatocellular carcinoma in HCV cirrhotic patients treated with direct acting antivirals. Dig Liver Dis 2019;51:310-317. doi:10.1016/j. dld.2018.10.014

22. Furuichi Y, Moriyasu F, Taira J, et al. Noninvasive diagnostic method for idiopathic portal hypertension based on measurements of liver and spleen stiffness by ARFI elastography. J Gastroenterol 2013;48:10611068. doi:10.1007/s00535-012-0703-Z

23. Sugimoto K, Moriyasu F, Oshiro H, et al. Viscoelasticity measurement in rat livers using shear wave US elastography. Ultrasound Med Biol 2018;44:2018-2024. doi:10.1016/j.ultrasmedbio.2018.05.008

24. Arena U, Vizzutti F, Corti G, et al. Acute viral hepatitis increases liver stiffness values measured by transient elastography. Hepatology 2008;47:380-384. doi:10.1002/hep.22007

25. Raizner A, Shillingford N, Mitchell PD, et al. Hepatic Inflammation May Influence Liver Stiffness Measurements by Transient Elastography in 
Children and Young Adults. J Pediatr Gastroenterol Nutr 2017;64:512 517. doi:10.1097/MPG.0000000000001376

26. Millonig G, Reimann FM, Friedrich S, et al. Extrahepatic cholestasis increases liver stiffness (Fibro Scan) irrespective of fibrosis. Hepatology 2008;48:1718-1723. doi:10.1002/hep.22577
27. Kubo K, Kawakami H, Kuwatani M, et al. Liver elasticity measurement before and after biliary drainage in patients with obstructive jaundice: a prospective cohort studya prospective cohort study. BMC Gastroenterol 2016;16:65. doi:10.1186/s12876-016-0479-3 